\title{
STANDARDISATION, INNOVATION AND IMPLEMENTATION OF INFORMATION TECHNOLOGY
}

\author{
Kai Jakobs ${ }^{1}$, Rob Procter ${ }^{2}$, Robin Williams ${ }^{2}$ \\ 1) Computer Science Department, Technical University of Aachen, Germany. \\ 2) Department of Computer Science, The University of Edinburgh, Scotland.
}

\begin{abstract}
This paper looks at the mutual interplay between information technology (IT) and its environment. Exploring specifically the issues surrounding innovations in the field of corporate IT systems we show that a distinction has to be made between different categories of information technology (IT) systems regarding their introduction, subsequent diffusion, and particularly their corporate usage. We will show that strategic deployment of e-mail will only happen if and when it is no longer considered an infrastructural technology. However, apparently this has rarely happened thus far.
\end{abstract}

Strong relations and dependencies exist between standardisation, innovation and the subsequent implementation of IT systems. We argue that these activities must not be considered separately, especially as standards-based components are playing an increasingly important role in implementation processes. Consequently, the role of the users in, and their influence on, standards-setting are also addressed.

The findings and conclusions presented are largely based on a number of interviews with large corporate users of e-mail systems.

\section{SOME INTRODUCTORY CONSIDERATIONS}

Technological artefacts in general, and especially such powerful representatives as IT systems, will exert potentially strong impact on their environment. Complex interaction can be observed, where technology may assume both an active and a passive role; that is, technological artefacts and their environment are mutually interdependent. The environment within which technology is used and employed has, among others, social, cultural, societal, and organisational bahaviours, rules and norms. It is clear that 
technology cannot emerge completely independent from such external influences. However, the impact IT may have on organisations, or indeed society as a whole, has thus far attracted considerably more attention than the powers that shape this technology in the first place. Especially the impact of IT within organisational settings (e.g. on a company's performance, or its role as an enabler of business process re-engineering) has been subject to a vast number of studies and analyses. Keywords such as 'management of change', 'technology management' and 'organisational transformation' can frequently be found in the literature, typically denoting studies on how the introduction and subsequent use of IT have changed a particular organisational environment - for better or worse. Only recently has the reverse direction of impact been studied, i.e. the one exerted from organisational and societal conditions on technology.

\subsection{The social shaping of technology}

Two mutually exclusive schools have dominated research on technology and organisations until the early eighties (and are still in evidence). Proponents of the 'organisational choice' model consider technology as a vehicle to both reflect and foster the interests of particular groups; the process of change can be, and indeed is, shaped entirely by policy makers or organisation's managers; these actors have unlimited technological choices. "Technology has no impact on people or performance in an organisation independent of the purposes of those who would use it, and the responses of those who have to work with it" (Buchanan \& Huczynski 1985). In contrast, 'technological determinism' in essence postulates that IT determines the behaviour of organisations, that the consequences of manipulating a given technology will always be the same, independent of who manipulates and within which context (Watad \& Ospina 1996). It follows that, according to this view, organisations have little choice but to adapt to the requirements of technology; particular paths of technological development are inevitable; like organisations, society at large also has no other choice but to adapt.

Research into the social shaping of technology (SST) largely emerged as a response to technological determinism. SST adopts a middle course between the two older approaches, acknowledging that technology indeed has an impact on its environment, but that at the same time it is well framed through technical, but rather more through, for example, organisational, 
societal, cultural and economic factors (Williams 1997). In particular, SST attempts to unveil the interactions between these technical and social factors. Abandoning the idea of inevitable technological developments implies that choices can be made regarding, for instance, the acquisition, the use and particularly the design of technological artefacts. There may be a broad variety of reasons upon which these choices may be based. In an organisational context this may include purely technical reasons as, for example, the need to integrate legacy systems, but decisions may also take into account company particularities, as for instance organisational or reporting structures ${ }^{1}$. These choices, in turn, may lead to different impacts on the respective social or organisational environments. Thus, studying what shaped the particular technology offers a chance to proactively manipulate that very impact expected to result from this particular choice. At the same time this capability should also contribute to the prediction - and thus prevention - of undesirable side effects potentially resulting from a new technology. Technology tends to have other effects besides those actually intended, these effects need to be explored as well. On the other hand, the respective environment shapes technical artefacts and systems during design and in use, i.e. at the site of the actual implementation. The overall process that comprises the first design stage (of an invention), its production and the final implementation can be referred to as 'innovation'. It is this process I will now look to.

\subsection{Configurational technology}

In today's networked environment technological systems are becoming increasingly complex. Some of these systems evolve into what has been called 'generic technological systems'; prominent examples include railroads, power supply and telecommunication networks (Fleck 1995) ${ }^{2}$. Such systems are not a coherent whole, rather, they have been established through the interconnection and interoperation of a large number of smaller systems, which are easier to handle, to manage and to modify. These smaller systems then need to be integrated into the overall system; often they are interconnected through dedicated interworking units. There is an obvious need for standards in such environments, which typically involve different technologies from different vendors. Without standards it would be impossible to achieve interoperability at the required scale. On the other hand, high-level standards may also emerge from such complex systems. 
These standards will be at system level, incorporating the single component and interface standards. The need for the single components to cooperate smoothly also leads to 'natural trajectories' of development (as e.g. mechanisation or economies of scale (Fleck 1988)). Here, a technological bottleneck in a certain area can hamper the progress of the overall system. Thus, this bottleneck will attract the attention of a number of entities trying to solve the problem. This, in turn, will lead to progress in this particular field, possibly leaving behind others, on which interest and innovation efforts will subsequently concentrate. These gradual improvements are characteristic for generic systems, which typically exhibit their high degree of standardisation not least due to technological 'path dependencies'.

Some large systems, however, may not follow such trajectories. Typically, each of them is particularly well integrated into its local environment, and closely follows this environment's particular contingencies; that is, these systems are configured to optimally meet the respective local requirements. Such close adaptation to a local context is likely to lower the general interest in such systems, which implies that they will not generate any large-scale standardisation activity. Implementation of such systems requires considerable efforts, and would be next to impossible without far-ranging input from users, who are the only ones to know their environment sufficiently well. It is especially in those cases that the site of an implementation at the same time is a site of considerable innovation; in fact, the implementation itself becomes a source of innovation, as additional innovations become necessary for the adaptation to the local context. As a result, the distinction between innovation and implementation becomes meaningless in this environment, and the processes of invention, innovation and diffusion collapse into a process coined 'innofusion', with feedback occurring primarily through internal learning processes (Fleck 1988). Such systems are referred to as 'configurational'; they have been configured from a wide range of components, from different vendors to optimally meet the need of their local environment. Most likely, given the customised nature of the system, some, maybe even the majority of components have been developed in-house.

Throughout the remainder of the paper we will first discuss the different characteristics and properties of two different classes of technology. Chapter two introduces the important distinction between generic and specific IT services. Subsequently, the importance of standardisation especially for the 
latter is discussed in chapter three. Finally, chapter four will give some brief conclusions.

\section{INFRASTRUCTURAL AND BUSINESS RELEVANT TECHNOLOGIES}

Elsewhere we have discussed the surprisingly indifferent attitude of corporate users regarding the use of electronic messaging systems that may be observed for many companies (e.g. Jakobs 1996). The search for an explanation first leads to the observation that large organisations deploy technology in very different contexts for very different purposes. This holds for technology in general, and all the more for IT. IT artefacts can be found on plant floors, in R\&D labs, and on secretaries' desktops; the different purposes they serve include production automation, number-crunching, and accountancy. Despite these different application areas, at a very general level IT artefacts may be categorised as being either 'specific' or 'generic', i.e. 'business relevant' or 'infrastructural'. A car manufacturer's robot may serve as a representative of the former, a secretary's fax machine as a typical example of the latter. In particular, a company's communication system (e.g. the internal telephone network, or the corporate e-mail system) is in many cases considered as being infrastructural technology (Jakobs 1997).

Neglecting the crucial enabling role of an adequate infrastructure has in many cases led to an environment where investment in infrastructure technology is given low priority (Benjamin \& Levinson 1993). This is a pretty short-sighted approach, though, as almost all applications depend on an underlying communication infrastructure. This holds not only for intraorganisational communication, but is becoming increasingly important for inter-organisational information exchange as well. Ideally, an infrastructure supports common processes and business applications not only within a single corporation, but across organisational boundaries, where a company and its customers and suppliers share a common infrastructure upon which common applications can be built (as e.g. EDI). Indeed, the need to quantify the corporate benefits to be gained in several cases hampered this attempt to upgrade a corporate e-mail system (which is part of the 'infrastructure'. Whilst any organisation would collapse without a proper infrastructure, investments in this area are harder to justify as they will only result in 
intangible benefits, and are unlikely to yield an observable, or quantifiable, return on investment.

It may be assumed from the above that for the time being extensive 'infrastructural' implementations may only rarely be anticipated. It appears that they simply do not attract an interest similar to the one observable for 'business relevant' technology. In the following this assumption will be further examined by looking at the problem from the innovation theory angle.

Which technological systems are actually considered as 'business relevant' by a company very much depends on the respective organisation's commercial interests. Accordingly, this will vary between companies; a car manufacturer, for example, may look to robots or systems for Computer Integrated Manufacturing (CIM), a publisher may be interested in Desktop Publishing equipment, and an innovative bottling line might attract a brewer. However, 'business relevant' has a broader scope than these purely production-oriented technical systems. In the service industry EDI may well fall into this category as well. In the banking and retail sectors, for example, it has already streamlined both intra- and inter-organisational processes to a considerable extent, a development which may be supposed to continue (Webs 1995). The same sector was, for instance, among the earliest industries to use mainframes, which have long since been seen as being crucial thanks to their ability to process massive amounts of financial transactions and to handle large volumes of data (Barra 1994). In particular, this shows that a system considered by one company as being 'business relevant' may well have 'infrastructural' status for another, a phenomenon that may, for example, be observed in the case of e-mail where perceptions regarding its business value differ widely between firms.

For each company technologies that relate to its core business - and its core competence - will naturally attract most interest, particularly if they hold the prospect of a quantifiable return on investment. Biervert \& Monse (1992) note that although demand for standard software has been growing faster than that for special customised software systems, tailor-made solutions are still preferred if the system is "... affecting the primary business of firms, especially for areas closely linked to production and marketing ..." (Busch 1989). It is primarily in these areas that companies are willing to invest most heavily. This holds particularly if such investments require major 
involvement of scarce (human) in-house resources. In fact, a company will only be able to implement new technology if adequate experience and expertise, both at engineering and managerial level are available locally (Biervert \& Monse 1992).

Moreover, a company is likely to have developed very specific requirements and processes primarily in the areas of its core business interests, which, in turn, stand in the way of a straightforward installation of a system. It is here where long-standing, time-honoured traditions characterise the environment, and where technical systems as well as production and business processes have been designed to optimally meet the demands of their specific environment. A new system to be implemented here will have to be customised to a similar degree as have been the other artefacts in this environment. It is unlikely that standard components will provide the required functionality. Accordingly, it may be concluded that innovations are most likely to occur under these circumstances, i.e. when 'business relevant' technology is to be implemented. Indeed, it appears that recent research into innovations has almost exclusively focussed on what must be considered as 'business relevant' technologies, including robots for manufacturing plants (Fleck 1988), corporate cash management, home and office banking (Fincham 1994) in banking, and CIM in manufacturing (Blumberg \& Gerwin 1994).

It has been mentioned above that 'infrastructural' artefacts may come from a wide range of items, their major common characteristic being the fact that they are not, or only to a very small extent, integrated into business processes. Typically, they are more or less equally useful for everyone, irrespective of his/her particular background or specific environments. Consequently, they are not normally subjected to well specified contextspecific requirements as are the 'business relevant' ones. This, in turn, holds the prospect of a higher degree of freedom for the designers and implementers, possibly to the extent of reducing implementation to a mere installation of components, without the need for any further innovation.

Our case studies have also shown that only those few companies which consider e-mail as a strategic tool, i.e. as 'business relevant' are prepared to go an extra mile to implement a system that really meets their needs. This situation is highlighted by the representative of one of these companies, who remarked that his organisation frequently had to build their own innovator 
level tools to achieve the desired functionality despite inadequate products. In contrast to that, an e-mail system not considered as 'business relevant' has been a matter of buying off-the-shelf for other companies.

Two conclusions may be drawn from the above:

- There is a need to differentiate between different categories of technology.

- Users are more prepared to invest in 'business relevant' technologies.

The above findings suggest that Biervert's observation that “... it is unusual for a firm to go into developing and pursuing strategies for the development of technology when its main line of business lies elsewhere ...." (Biervert \& Monse 1992) is not quite correct. Rather, irrespective of a company's core business it appears that the perceived strategic importance of an IT system is the yardstick by which a company's willingness to start its own development activities has to be measured - i.e. whether it is classified as 'business relevant' or 'infrastructural'. Accordingly, a dedicated e-mail strategy - one which goes well beyond simply purchasing the same off-the-shelf system most others buy and interconnecting it to the largest service provider available - requires the recognition of e-mail as a strategic service as a necessary condition in the first place. For a sufficient condition a user company also needs to be able to contribute its specific competence to the implementation process, i.e. primarily an in-depth knowledge of its particular needs and of the characteristics of its specific local environment.

\section{STANDARDS AND INNOVATIONS}

In those cases where a suitable combination of standardised components meets the needs of a particular environment standards ${ }^{3}$ establish the sole framework within which an implementation takes place. This is most likely to happen in case of 'infrastructural' artefacts or systems, with only a small likelihood of, and indeed need for, innovations. Alternatively, especially if 'business relevant' systems are concerned, standards may be considered as contributors to a system implementation, and to potential innovations. Again, this contribution will be through single components, as overall, system-wide standards are most unlikely to materialise for complex ITsystems. Yet, this time these components will only play a minor role in the 
overall implementation, as the major efforts will (have to) go into the implementation of the overall system, that is, into the adaptation of the system to its environment.

To accept the proposition that future IT systems will to a considerable extent be based on international standards implies the need to look at the ways how standards are formed and established in order to understand what is going to shape future technology, and especially ICT. As a consequence we would suggest that the site of the user's implementation as the current major locus where innovations materialise, and where social shaping accordingly takes place, will to some extent be complemented by activities of the standards committees, where the underlying groundwork upon which innovations will draw has to be done. In the case of electronic mail systems, for instance, much of the underlying transport system comprises exclusively of standardised components. Here, standards firmly establish the framework within which implementations take place (with little, if any, need for innovation). Regarding the more application-oriented parts of the overall system, i.e. the e-mail service itself, we note that implementation-specific particularities become more important; it is primarily at this level where the integration into the existing IT environment takes place.

In any case, it follows that standardisation processes are important for innovations, and that they must not be ignored when discussing implementation and innovation processes. Now I would like to go one step further and suggest that major similarities exist between innovation and standardisation processes. Indeed, it may well be possible that lessons learned from the well-researched field of innovation may be applied to standardisation processes, and vice versa. This proposition may appear to be a little far-fetched; after all, it could be claimed that there is a major, decisive distinction between the processes of standardisation and innovation - their respective scope. Whilst this is certainly true, there are indeed major similarities between the two processes as well.

For one, users have a considerable influence on innovations; a user may have commissioned a technological system the development of which requires innovations, or an innovation emerges on his premises as part of an implementation project, or he develops a genuine innovation in an attempt to overcome identified deficiencies of the available technology. Yet, it is frequently overlooked that users (could) have a similarly strong hold over 
the industry simply because of their purchasing power (although they are not necessarily aware of it (Ferné 1995)). It follows that they could establish themselves in a position to dominate innovation and standards setting processes alike. As it currently stands, however, users' different needs prevent them from playing the important role they could play - at least in standards setting.

As committee members (including those from user companies) tend to see themselves as company representatives (as opposed to, for example, representatives of the user community), they only contribute specific requirements that originated form their respective environments (Jakobs 1997). That is, we can observe here that the single local environments already have a major - albeit implicit - impact on the standards setting process in that they heavily influence the user requirements that are actually fed into the process. This impact in fact represents another correspondence between standards setting and innovation.

Moreover, both standardisation and innovations are major platforms for cooperation between vendors and users. Without this cooperation the outcome of the processes would most likely be far from satisfactory, due to the complementing roles users and vendors play, which are equivalent in both processes: it is the vendors' task to provide for the technical knowledge and expertise. Users, in turn, contribute their specific knowledge about their requirements and environments, respectively.

Another aspect of standardisation should not be forgotten either: not only will technological specifications be done in the committees, but other factors that may shape technology will be channelled into the work groups of the international standards setting bodies as well. The respective corporate environments of the committee members' employers, for instance, will play a major role in this context. The different visions of how a technology should be used, and the ideas how this can be achieved are both formed by these local environments. They will exert a significant impact on the work of the committees, thus preceding, and possibly complementing the local implementation context as a major source of influence. This holds especially in the case of anticipatory standards, which specify new services from scratch, and thus offer the opportunity to incorporate the particular characteristics of the originating committee to some degree. In a more extreme case, work within the committees may even anticipate innovations 
that would otherwise result from a local implementation. This may, for instance, happen if a strong user representative succeeds in promoting the particularities of his local environment as the basis for a standard. Yet, reactive standards will likewise transpose the environment from which they emerged; this will typically be the corporate environment of the inventor who specified the system upon which the standard will be based. Thus, his visions will implicitly be embodied in the standard specification. Again, the correspondence between implementation and standardisation is obvious, only in this case it is the vendor's environment that shapes the standard. It therefore comes as a surprise that this close relation between standardisation processes and innovations has so far been largely ignored.

Related to these observations, although on a personal rather than organisational level, we note that the processes leading to both, technical design and technical standards are typically developed by engineers, who in many cases lack an understanding of the non-technical components that need to be considered for both, designs and standards. The accordingly rather 'technology-centric' outcome of both processes has frequently been criticised.

We can now identify two distinct activities which have a major impact on innovations, namely the work done within the standards committees and the actual implementation itself. As we have observed above, these activities are not unrelated; even local implementations of individual, customised systems are likely to include standards-based components. Thus, standardisation will always influence innovations, either (see also Figure 1):

- directly, e.g. if an implementation is done via integration and configuration of standards-based components; or

- indirectly, in case of a customised solution comprising some standard elements being implemented; or

- as the actual locus of innovations. 


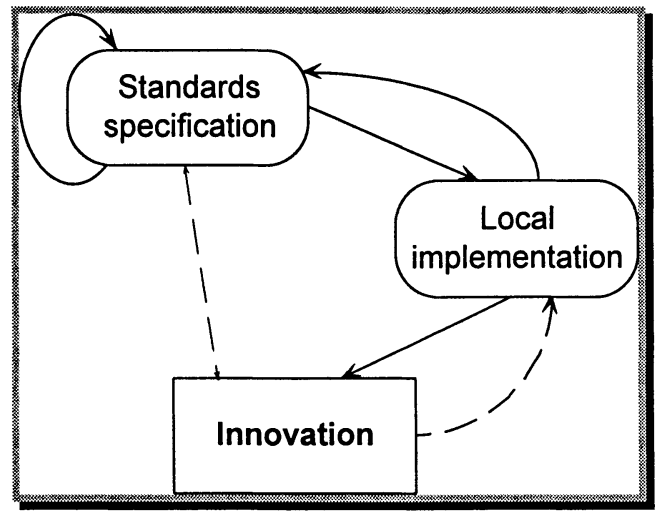

Figure 1: Standardisations' Influence on Innovation and Implementation

In fact, given the large number of standardised components available, the odds are that every innovation in the IT sector will at least in part be influenced by standardisation.

\section{USERS AND STANDARDISATION - SOME CONCLUDING(?) REMARKS}

'Requirements' is a very broad term, that not only refers to the technical domain, but is also closely linked to the particularities of the respective local environment. Accordingly, providing only functional and technical requirements does not suffice. Rather, organisational and other non-technical needs have to be considered, and user representatives need to be in a position to identify these needs. Thus, it would not make too much sense if only technical people were sent to the committees to represent users. Rather, corporate strategists and managers also need to get involved, to make sure that the non-technical issues are adequately covered as well.

If a user actually does participate, assuming the role of a user representative, as opposed to representing only a single company, survey findings show s/he will face credibility and communication problems. First, many respondents said they would need to be convinced of a proper mandate, to show that not just a particular company's special requirements are brought into the process, but more widely identified needs ${ }^{4}$. Typically, companies are sending their engineers to standards committees, and their views tend to be 
somewhat 'techno-centric' (Morell \& Stewart 1996). Thus, it is not too surprising that committee members have named technical sophistication on the side of the user representatives as a major prerequisite for meaningful participation. Thus, it would be necessary to convince committee members that representing a user in a standards committee does not necessarily require technical expertise, and that there are more aspects to standards than just purely technical functionality. Failing on the users' side to adequately address these issues will invariably weaken their position in the committee ${ }^{5}$.

A major underlying obstacle here is rooted in a communication problem, and in the differences in views and perceptions of technology that can be identified between engineers and managers. Such problems in 'crossprofession' communication are not uncommon, to solve them requires learning by all sides; engineers need to gain some understanding of the necessary organisational and managerial considerations, and managers need to get an understanding of at least the technological basics. This may sound trivial, but the reported major credibility and acceptance problems from which ITU-T's Study Group I, and its ISO sister group, suffered finally contributed to the abandoning of these groups (which had been charged with specifying user requirements).

As a consequence of the typical history of corporate deployment of e-mail, and of its perception as being primarily infrastructural, users will not only be unable to contribute initial requirements to a new standards setting initiative (others than very general ones), but they will also be unable to provide useful input for quite some time afterwards ${ }^{6}$. This situation can only change if and when the status of e-mail (and of other IT systems with a similar corporate history) switches from 'infrastructural' to 'business relevant'. Even if this happens, it will subsequently take a considerable period of time to actually identify new, more advanced requirements. Although some are likely to emerge during implementation, others will only surface once the system has been adapted to, and especially integrated into, the local environment (e.g. into business processes) and experiences have been gained through its use, a process which may well take years.

If users are not (yet) in the position to contribute requirements, the standards setting process will not benefit very much from their participation. Therefore, we may conclude that in this case it will make little, if any, difference whether or not user representatives participate in the process, 
since they can only assume the role of technical experts - rather than that of a contributor of requirements - many of whom will be on the committee anyway (representing vendors). It follows from the above that this situation may easily occur in case of 'infrastructural' technologies, where users do not see any business incentive to contribute to standards setting. This additional lack of incentive comes on top of the reluctance caused by the general perception of the standardisation process as slow, inefficient, costly and yielding uncertain results (e.g. Ferné 1995).

The generally accepted principal role for user representatives in standards setting is to provide real-world requirements (e.g. Naemura 1995). However, in most cases specific functional requirements are not normally available at the beginning of a standardisation project. Moreover, from the above discussion we have seen that unconditional user participation in standardisation is not a desirable goal per se, thanks to the largely contextspecific - and thus very diverse - requirements that are to be expected. Instead, ways need to be found to achieve meaningful user representation.

Given the huge variety of business sectors, organisational forms and business philosophies, the many different intra- and inter-organisational interdepend-encies, and all the differences that come with varying company sizes, not to mention regional or national differences in culture and legislation it is most unlikely that coherent requirements will ever materialise, apart from some very generic ones. Moreover, representatives of user companies do not necessarily see themselves as user envoys in general; rather, they are representing their respective employers. Therefore, there is a need for a mechanism to align the various requirements.

These considerations suggest that users should seek representation through a dedicated body (a 'user coalition'), responsible for voicing its stakeholders' needs and concerns in the appropriate standards committees. Great care needs to be taken to ensure that such a body actually represents as broad a variety of users as possible, of all sizes and from all sectors, rather than acting as something similar to, say, a trade association representing only a single market sector. This broad market coverage is crucial for several reasons. For example, even basic requirements will differ between SMEs and large enterprises. 
There is also an economic dimension to this way of user representation, in that it offers the almost only realistic chance for those user companies which cannot afford direct participation to have their requirements filed with standards committees. Again, this holds particularly for SMEs, almost all of which currently stay clear of any standardisation-related activities. Finally, it will serve to reassure other committee members (i.e. representatives from vendor companies) that indeed a broad base of users is represented. Clearly, the alignment of requirements has to take place prior to actual standardisation to enable the user community to file an agreed set of requirements, and to speak with one voice, rather than engage in turf-wars during the actual standards setting process.

The observations above should trigger some further thoughts regarding the general desirability of direct user participation in standards setting, and indeed on the overall structure of this process.

\section{NOTES}

1 Local cultural norms may also be very influential. The ways how information systems are used in Chinese companies, for example, differs considerably from those in Western cultures (Martinsons \& Revenaugh 1996). IS is shown to be used to reinforce and strengthen managerial power in the former, whereas broad access to information serves rather more as a leveller in the latter.

2 Whether telecommunication networks are indeed 'generic' may require additional discussion. In particular, it appears somewhat questionable whether it actually makes sense to consider such an extremely complex and heterogeneous structure like the GII as one 'generic' system (in the sense of 'a system where standardisation takes place at the overall level' as, albeit indirectly, suggested in e.g. (Fleck 92)). I would argue that even in the far less complex case of e-mail, for example, a service which forms only a tiny part of the GII, there is no such thing as system-level standardisation. Considering the overall e-mail system, we find that it comprises a number of very different artefacts; including LAN- and mainframe-based systems, gateways, a wide range of end-systems, and backbone networks. This conglomeration of very heterogeneous artefacts, serving different purposes cannot be subject to one overarching, systemlevel standard.

3 Please note that the term 'standard' refers to the output of the 'official' international bodies, including e.g. ISO and ITU. In particular, it does not include what is commonly termed 'proprietary standard' or 'industry standard'.

4 It is worth noting here that apparently no such mandates are necessary for representatives of vendors and service providers. This may again be interpreted as an expression of the predominantly 'techno-centric' attitude of standards setting committees, whose vast majority of members is representing vendors or service providers. Their roles have never been questioned, although they obviously 
include the representation of the respective employers' commercial interests (which may or may not be in line with the overall best interest).

5 Despite the frequently voiced condition that users need to be technically sophisticated committee members also reported that a proposal's technical merits are significantly less important than the presence of its proponents at meetings (with the exception of the IETF, where technical merits is the one thing that counts). It might be suspected that 'technical sophistication' is put forward as an excuse to help keep users away from the committees. This would, however, need further data to work from.

6 It has been shown (in e.g. (Jak 96)) that it may well take years for an organisation to develop a reasonably good understanding of its technical requirements on e-mail (only a very small percentage of the companies represented in the survey were in a position to identify more advanced requirements even after several years of usage).

\section{REFERENCES}

Benjamin, R.I. \& Levinson, L.( 1993) A Framework for Managing IT-Enabled Change. Sloan Manayement Review Summer 1993.

Biervert, B. \& Monse, K.(1992) Creating applications of information technology in the service sector. In: Dierkes, M. \& Hoffmann, U. (eds) New technologies at the outset - social forces in the shaping of technological innovations. Campus/ Westview.

Blumberg, M. \& Gerwin, D. (1994) Coping with Advanced Manufacturing Technology. In: Rhodes, E. and Wield, D. (eds) Implementing new technologies. Blackwell Ltd.

Buchanan, D.A. \& Huczynski, A.A. (1985) Organizational Behaviour. Prentice Hall.

Ferné, G.: (1995) Information technology standardization and users: international challenges move the process forward. In: Kahin, B. \& Abbate, J. (eds) Standards policy for information infrastructure. MIT Press.

Fincham, R. et al. (1994) Expertise and innovation - information technology strategies in the financial services sector. Oxford U. Press.

Fleck, J. (1988) Innofusion or diffusation: the nature of technological development in robotics". Edinburgh U. PICT Working Paper, no. 4.

Fleck, J. (1995) Configurations and standardization. In: Esser, J. and Fleischmann, G. (eds) Soziale und ökonomische Konflikte in Standardisierungsprozessen. Campus.

Jakobs, K., et al (1996) Corporate e-mail in Europe - requirements, usage and ways ahead. Proc. 4th Int. Conf. on Telecommunication Systems, Modelling and Analysis.

Jakobs, K. (1997) User participation in standardisation processes - impact, problems and benefits. Internal WP, Edinburgh U. 
Martinsons, M.G. \& Revenaugh, D.L. (1996) The impact of societal culture on IS planning and implementation. Proc. 2nd Americas Conference on Information Systems AIS '96.

Morell, J.A. \& Stewart, S.L. (1996) Standards development for information technology: best practices for the United States. ACM StandardView 4(1).

Naemura, K. (1995) User involvement in the lifecycle of information technology and telecommunication standards. In: Hawkins, R.W. et al. (eds) Standards, Innovation and Competitiveness. Edward Elgar Publishers.

Watad, M. \& Ospina, S. (1996) Information technology and organisational change: the role of context in moderating change enabled by technology. In: Diffusion and Adoption of Information Technology. Chapman \& Hall.

Williams, R. (1997) The social shaping of information and communications technologies. In: Kubicek, H. et al. (eds.) The social shaping of the information superhighways. Proceedings of International Conference, COST A4. European Commission DGXIII, Luxembourg. 